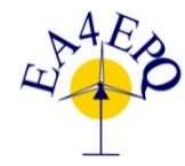

\title{
Integration of maintainability and operativity criteria in the contracts to build under EPC model in energy infrastructures to optimize the OPEX. Example of the methodology to analyse the preferences in the owner and contractor point of view.
}

\author{
Jesus Losada Maseda ${ }^{1}$, Almudena Filgueira Vizoso ${ }^{2}$, Eugenio Muñoz Camacho ${ }^{3}$, Laura \\ Castro Santos ${ }^{4}$, Francisco Javier López Montero ${ }^{5}$.
}

1. PhD industrial Engineer by the Coruña University, Spain. Project and business development manager of Reganosa (www.reganosa.com). Email: jlosada@reganosa.com

2. PhD industrial Engineer by the Coruña University, Spain. Chemical Engineering department. Chemical department of the Coruña University. Email: almudena.filgueira.vizoso@udc.es

3. PhD industrial Engineer by the Madrid Polytechnic University (UPM). Full Professor in the Universidad a

Distancia (UNED) in the Chemical Engineering Department. Email: e.munoz@ind.uned.es

4. PhD industrial Engineer by the Coruña University, Spain. Chemical Engineering department. Chemical department of the Coruña University.

5. PhD student industrial Engineer by the Coruña University, Spain. Chemical Engineering department.

Chemical department of the Coruña University.

\begin{abstract}
The buyer of Project or equipment wants to obtain the maximum profit for the money that is invested in the operation and the seller shall try to give the less for that money to obtain also the maximum benefit. The way both parties regulate their relation is based in the agreement under a contract base, that in the energy infrastructure sector is mostly based in the EPC (Engineering Procurement and Construction) model.

The present paper uses the information and data obtained through the development of the $\mathrm{PhD}$ thesis of one of the authors, that collected valuable information and assessment about the integration of operability and maintainability criteria in the contracts of a total of 158 projects and megaprojects, with a total contract value close to $40.000 \mathrm{M} €$. Several of those projects correspond to windmill, solar and hydraulic power plants.

The survey done collected information about the perception and point of view of the promoter or owner, the contractor or the supplier, the engineering companies (Project Management Team (PMT)) and several advisors (legal, commercial,..), about the preference of integration of those criteria in the projects that they were involved in, and the phase and the procedure to make the integration, as well as the role of experienced personnel in Operation and Maintenance areas in the whole life time of the projects.

The conclusion of the study confirmed that the perception of what the owner and the contractor understand about the integration of operation and maintenance criteria in the projects is really different, but if contractors and/or suppliers would try to understand and deliver at a reasonable price what the owner is expecting from them, their chance to become the preferred contractor in the tenders associated to the projects would be increased.
\end{abstract}

Key words: EPC, Contract, Operability, maintainability . 


\section{Introduction}

As the general conclusion of the research work performed by the authors and reviewers of the $\mathrm{PhD}$ thesis [1] that supports this article, it could be summarized that all the stakeholders involved in the development of relevant projects and megaprojects (owner, contractor, technical, economic and legal advisors,...) concluded that the integration in different phases of the projects and also in the preparation of the tendering documentation of experienced personnel in the operation and maintenance area of the future assets to be delivered, especially in the commissioning and start-up phase, would add value to the project itself.

This article is the second one of a set of five that will be developed under the new research areas initiated with the publication of the referenced $\mathrm{PhD}$ Thesis.

The main objective of the article is to present some of the operation and maintenance criteria considered in the global analysis and identify the relevance and priority that Owners and Contractors assign to them, presenting a final ranking ordered by relative preference of the criteria and comparing and analysing the point of view of the different stakeholders that determine their position in the raking.

\section{Background}

The identification of the operation and maintenance criteria that must or should be integrated and used in a project depends basically in two factors:

- The experience and knowledge level in the operation and maintenance areas that the parties involved in the project may have. These condition is not limited only to pure operation and maintenance aspects, but also involve security and safety concerns, intellectual property protection, and how that knowledge and experience is managed inside the organization (talent management)

In terms of the level of expertise and knowledge that it is requested to manage a contract, it should be highlighted the need to understand what it is written in the contract and project related documents, that it is normally named as "readability".

Based in the conclusions of the study done by the authors [2], the readability level of the contracts written in Spanish language is lower than the level achieved by the contracts written in English Language. This means that the level of education required to understand the contracts should be higher in the Spanish language ones.

- The use of the common sense, the less common of the senses, to identify and solve in advance any problem related with the future activity in the asset or equipment to be built or delivered by the Contractor or the supplier, avoiding the introduction of changes once the design or construction phase may have started, as it might generate unacceptable extra costs and delays.

The basis used to select and include the operation and maintenance criteria that were used to develop the survey are founded in the experience of the authors in the definition, management, analysis and control of energy infrastructure projects, accumulating more than 10 references with a total contractual value of more than 4.000 M€.

\subsection{Description of the operation and maintenance criteria.}

Based in the unique conditions of the referenced Projects and personal interviews hold with several specialists in the area, a total of 15 operation and maintenance criteria were identified. Those criteria are related with OPEX optimization studies, the elaboration of the operation and maintenance manuals or the development of 3D models to review accessibility, escape routes or maintainability of the facilitates.

\section{Survey research}

\subsection{Strategy and approach to define the survey}

The survey used to measure the level of integration of operation and maintenance criteria in EPC contracts was focused and designed considering the conditions of the potential receivers:

- Multi-nationalities and locations, making the survey in English and Spanish language, allowing the participants to select their preferred language, using an online tool.

- Professional heterogeneric, so the survey allowed the participants to select and reply only the questions related with their own experience and background 
- Confidentiality, in order to protect the identity of the participants and the particular data of each Project.

\subsection{Summary of the data collected}

The total number of questions and answers included in the survey is

- Number of questions:

- Number of potential replays:

252

The number of surveys sent to people with proven experience and with potential interest to participate was 704.

The most relevant data that summarizes the information collected is:

- A total of 202 people participated. The 91\% were male and the 9\% were female.

- The people that participated in the survey worked in a total of 120 companies of a total of 42 industrial sectors

- Sponsor companies from 23 different countries (65\% from Europe and US) and construction companies from 25 countries (64\% from Europe and US), participated in the Survey, adding the experience of developing projects in 36 different countries (55\% from Europe and US)

- The level of education that is more common among the participants in the engineering degree, reaching the $35 \%$ of the male participants and the $47 \%$ in the female case.

- The mean average age of the participants is 47,2 years, being in the case of the male responders 47,8 years and 41,7 years in case of the female participants.

- The mean value of years of experience in the male participants was 21,52 , reaching 14,3 years in case of the female participants. The total accumulated years of experience of all the participants in the survey is 4.166 years.

- It was possible to collect information from people with experience in the project management and operation y maintenance in LNG terminal and gas pipeline systems collaborated in the survey, with the participation of representatives of the $100 \%$ of the LNG terminals of Spain and representatives of the $80 \%$ of the LNG terminals of Europe.

- The companies where the participants develop their work had an accumulated turnover value between 159.010 $\mathrm{M} €$ and 198.920 M€ in 2015.

- A total of 158 projects were analysed, with

- Dates of signature of the contracts between 1960 and 2015 .

- The most common type of projects were EPC or lumpsum $(59,49 \%)$

- The accumulated total value of the contracts was in the range of $32.206 \mathrm{M} \$$ and $39.370 \mathrm{M} \$$

\subsection{Methodology to represent the participants perception.}

The analysis of the information collected through the survey was, itself, a challenge, as the heterogenic of the participants and the intention to collect perceptions and not deterministic data made complex its analysis, conclusions and representation in a simple and understandable way.

The methodology used is based in the principles and guidelines that the Global Reporting Initiative (GRI) [3] [4] proposes to use to develop the corporative sustainability reports. Not all the principles and steps defined in the referenced guidelines were used, as some of them were not applicable for the area of research, but the main graphical representation principles were considered.

A three-variable graphical representation is used together with the formulation included in the reference thesis [1]:

1. $\mathbf{X}$ axis, represents, for each question, the prioritization of each criteria with the rest of criteria.

2. Y axis represents, for each question, the positive or negative weighted value that each participant in the survey assigned to each criteria, but compared with the absolute addition of the weighted values of all the criteria and the willing or acceptance of the sponsors to pay to include such criteria or, in the case of the contractors, their acceptation to reduce partially their benefits in case they incorporate such criteria without increasing their bid price.

3. The size (diameter) of the sphere represents, for each question, the absolute weighted value of each criteria, compared with the rest of the criteria. 
The way the figures should be interpreted as per the trends that it is shown in next image:

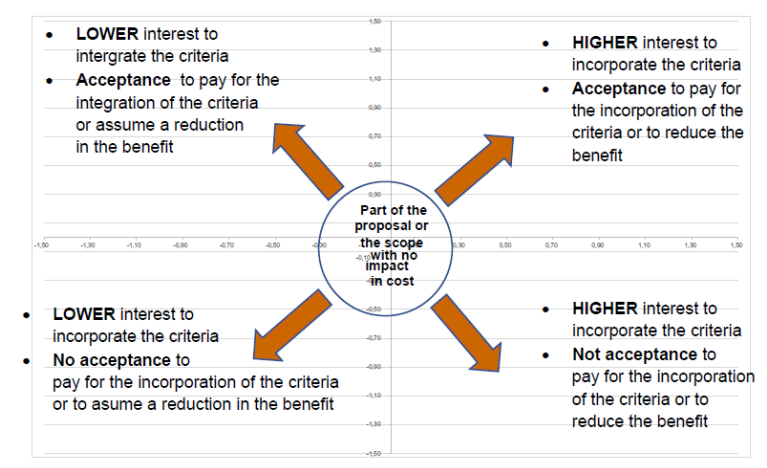

Figure 1: Guide to interpret the graphical representation of the evaluation of the operation and maintenance criteria.

\subsection{Survey to identify the use of the operation and maintenance criteria.}

For each of the 15 operation and maintenance criteria considered in the survey, a total of four questions and their replays were used.

The questions included in the survey were:

- Question 1. Please confirm if you may include into your scope of supply of your proposal next list of studies and works without increasing the price of the proposal, if they increase your probability to be awarded with the project.

- Question 2. Please confirm how much increment of the project cost you may assume for each of the next studies and works, if contractor include them in its proposal

- Question 3. Please confirm if you may assume the cost of each of the next criteria and works if the contractor includes them in its proposal, but they improve and optimize the project OPEX.

- Question 4. Please confirm if in the technical evaluation of the proposals it could have any positive impact the inclusion of next list of studies and works by contractor.

\section{Individual analysis of each operation and maintenance criteria}

Focusing to show the results of the analysis and avoiding extending too much this article, only one of the fifteen operation and maintenance criteria is represented, being possible to access the complete set of operation and maintenance criteria in the reference thesis [1]. The criteria that has been selected for this article is the one named as "Maintenance cost optimization study", as itself reflects the opposite approach and valuation for the Owner and for the Contractor.
The detailed and complete replays collected from the questions $1,2,3$ and 4 are included in the reference thesis [1].

Using the formula included in the reference thesis [1] and the representation criteria introduced in the point 3.3 of this article, the graphical representation of the analysis of the four questions, that collect the point of view of the Owner and the Contractor, is shown in next image.

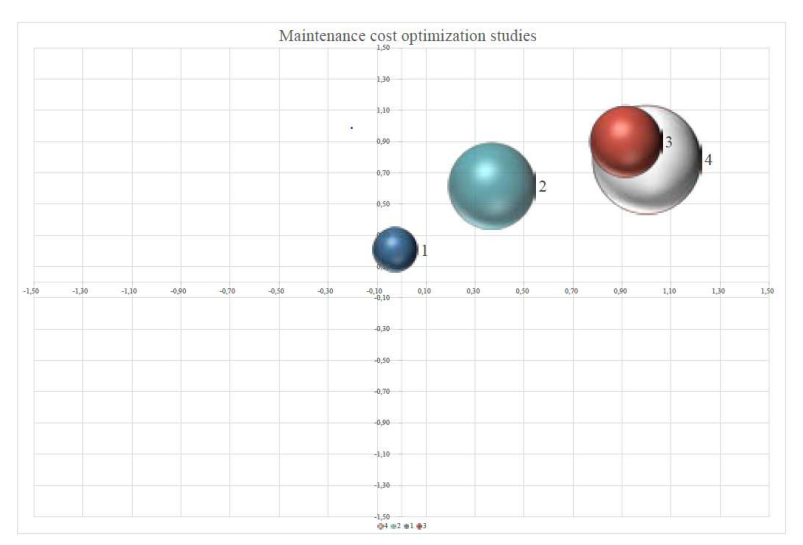

Figure 2:. Owner and Contractor evaluation of the Maintenance Costs optimization studies criteria.

Considering the location and size of the spheres included in the Figure 2 and considering the total number and weight of the replays collected, together with the interpretation criteria explained in the point 3.3 (Figure 1) of this article, next conclusions could be obtained:

\section{Contractor. Increase of awarding probability}

For Contractors, this criterion is not relevant. They consider that it might improve their probability to be awarded, but they are not willing to absorb the costs to develop such kind of studies, unless they are reimbursed or paid by the Owner.

In general, Contractors do not have in their organizations such kind of expertise that could perform these studies in house at a minimum cost, being necessary to subcontract this activity to specialized companies or to the vendors of the main equipment that they may bought, decreasing therefore their benefit margin for the project.

\section{Owner. Acceptation of the increment of the cost}

The approach shown by Contractor defers with the opinion of the property, that it is accepting to pay up to a $2 \%$ more for the contract price, if this increment is justified by an optimization of the project OPEX. 
The maximum extra cost to be accepted by Owner is limited to the improvement of the OPEX and the general improvement of the profit of the project.

\section{Owner. Acceptation of the increase of the cost by optimizing the OPEX}

In the Ownership point of view, the studies to improve and optimize the cost of the maintenance activities could optimize the OPEX of the project in the range of the $1 \%$ to the $5 \%$, as the cost of the spare parts and the duration of the downtimes could be reduced, as well as other several factors, being this compatible with the replays obtained for the question 2 .

\section{Owner. Improvement of the technical evaluation of contractor's proposals}

In the special case of this criteria, its incorporation in the Contractor proposal could increase the probability to improve the evaluation of the offer by the Owner in a range of the $1 \%$ to the $3 \%$, if it is demonstrated that the OPEX optimization can be achieved.

\section{Global evaluation of the operation and maintenance criteria}

Next figure represents the relative evaluation of the professionals that participated in the survey under the "Contractor" profile about the criteria "maintenance cost optimization studies" compared with the rest of the criteria analysed.

This figure does not represent the total of the fifteen operation and maintenance criteria analysed, in order to add clarify to the trend, being possible to get the complete picture in the reference thesis [1].

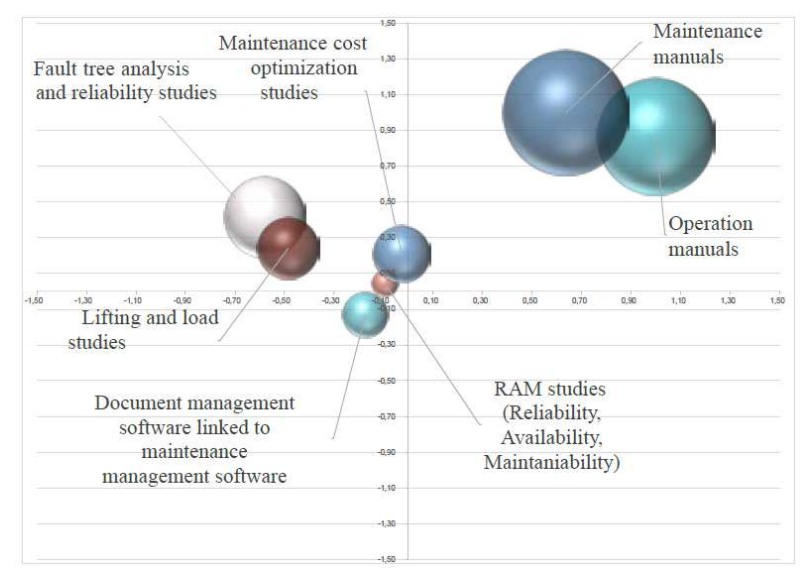

Figure 3:Global evaluation of the maintenance cost optimization studies under the Contractor point of view

From the Figure 3, it could be observed that the Contractor feels comfortable by delivering the operation and maintenance manuals of the facility or equipment that he will build, at it is the classical approach and he considers that it will not increase the cost or the risk of his proposal.

In the Contractor point of view any other study or analysis that could not be developed internally, being necessary to subcontract a specialist, and therefore reducing the Project Benefit margin, will not be prioritized and will not be considered as of its interest, non-including them in the proposal.

Next figure represents the relative evaluation of the professionals that participated in the survey under the profile of Owner, about the same criteria, "maintenance cost optimization studies" with the rest of the criteria analysed.

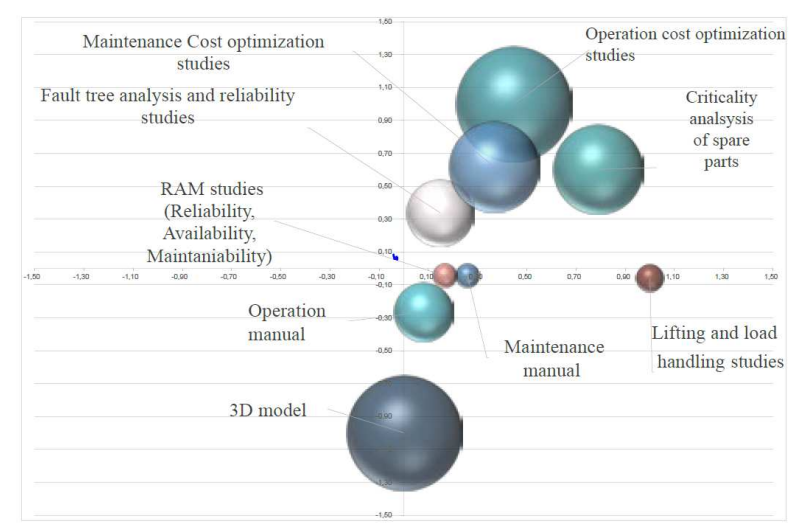

Figure 4:Global evaluation of the Maintenance cost optimization studies under the Owner point of view

For Owners or Sponsors becomes more attractive that Contractor includes under its scope of work the operation cost optimization studies and the critically analysis of the spare parts, that would minimize the cost and value of the stocked material and also minimize the time of unavailability due to critical and insurance spares run out, that may not be available in the warehouse due to their high costs and delivery time, or maybe due to the lack of analysis in their interchangeability.

\section{Raking of relevance of the operation and maintenance criteria.}

Next figure represents the relative and absolute weighted ranking of the criteria previously represented in Figure 3, as per next weight assignation methodology:

o X (priority); $20 \%$

o Y (acceptance to increase an increment in the project cost or to reduce the benefit margin): $40 \%$

o $\mathrm{Z}$ (global evaluation): $40 \%$

The values used in the weight assignation are base in the experience of the authors and the comments and recommendations collected in several 
interviews with some of the participants in the survey.

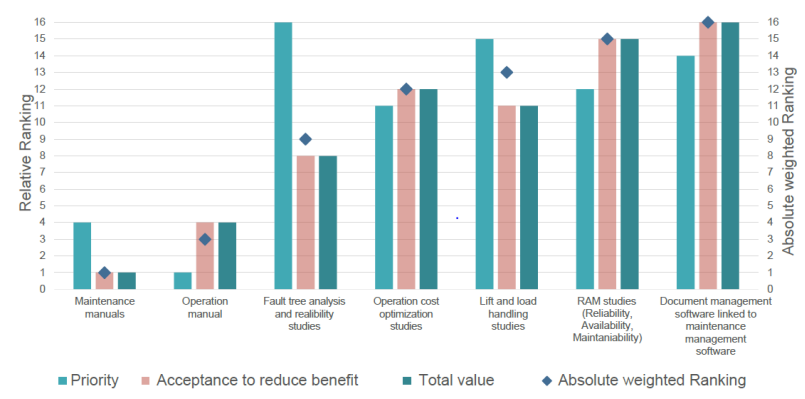

Figure 5: Ranking of priority of the evaluation of the operation and maintenance criteria under the contractor point of view.

Next table represents the comparison of the relative ranking of the previous criteria under Contractor and Owner point of view.

Table 1: Comparison of the prioritization ranking of some operation and maintenance criteria under the Contractor and Owner point of view.

\begin{tabular}{|c|c|c|}
\hline Name of criteria & $\begin{array}{c}\text { Contractor } \\
\text { (Question 1) }\end{array}$ & $\begin{array}{c}\text { Owner } \\
\text { (Question 2) }\end{array}$ \\
\hline Operation manual & 3 & 15 \\
\hline Maintenance manual & 1 & 8 \\
\hline $\begin{array}{c}\text { Maintenance cost optimization } \\
\text { studies }\end{array}$ & 12 & 3 \\
\hline
\end{tabular}

\section{Conclusions}

Any construction or development project for an industrial or energy infrastructure, of a complex equipment or even a common use equipment, shall be managed by a contract and some technical specifications that should define, as much clear as possible, what it is expected from both parties .

The balance and the harmony during the development time of the project could be achieved if the expectations of both parties are reasonable and well known, in what it could be named as "contractual empathy".

In a global world, where the competence to build or fabricate cheaper and cheaper is continuously increasing, those Contractors that would like to take some advantage and obtain some relevance, should offer a product that would exceed the expectations of the client and as it has been described in the present article, make his product (or project) be preferred and selected by the client, even being more expensive that other ones.

The integration since the very early development phases of persons with experience in the operation and maintenance of the products or projects to be delivered, may help to clarify and achieve agreements between contractors and owners, and will represent an opportunity to generate the differentia position from other competitors in front of the Owner as the way to optimize the profit and benefit of the project.

This innovative approach and strategy from the Contractor side to identify and supply what the clients are expecting is quite common on all those sectors where the name and the reputation of the vendor is no longer a differential advantage.

In the area of the energy infrastructure projects and particularly those related with natural gas, this new approach is being observed. A new market of consultancy services and support in any operation and maintenance areas is under development, as new owners and sponsors, with no experience and background references and knowledge are entering in the energy infrastructure business, but introducing more business aggressive and competitive requirements that were present in a classical regulated and protected market.

This new approach also responds to the requirement of those Contractors that want to match with the qualifying criteria introduced by Owners that request the integration of experts in the operation and maintenance areas of those facilities that will be delivered by contractor, including, under Contractors scope of work, in some of those projects the future operation and maintenance of the facilities under BOO or BOOT contracts, that will include this requirement for periods of time between 2 years to up to 25 years.

\section{References}

[1] Jesús Javier Losada Maseda, Almudena Filgueira Vizoso, Eugenio Muñoz Camacho "Incorporación de criterios de mantenibilidad y operatividad en la contratación de proyectos de construcción bajo la modalidad EPC en plantas industriales para la optimización de costes en la fase de explotación. Aplicación a plantas de regasificación de Gas Natural Licuado (GNL)" Tesis Doctoral de la Universidade de A Coruña, España, 2017.

[2] Evaluación del nivel de legibilidad de contratos EPC redactados en español e inglés para obras industriales. Jesús Javier Losada Maseda, Almudena Filgueira Vizoso. Revista de Llengua i Dret, Journal of Language and Law, núm. 66, 2016, p. 1-17. DOI:

[3] Reporting Principles and Standard Disclosures. www.globalreporting.org/information/g4/Page s/default.aspx

[4] Implementation Manual www.globalreporting.org/information/g4/Page s/default.aspx 